\title{
EXTENDING REDD+ TO MANGROVES AND WETLANDS FOR SMALL ISLAND STATES AND A CASE STUDY FOR THE CONSERVATION OF MANGROVES AND INTER-TIDAL MUDFLATS IN SINGAPORE
}

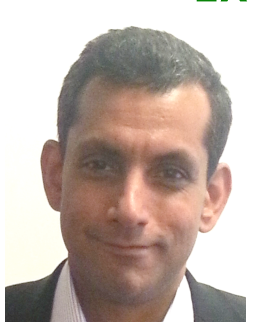

Vinayagan Dharmarajah

Environmental Law \& Policy Coordinator

Nature Society (Singapore)

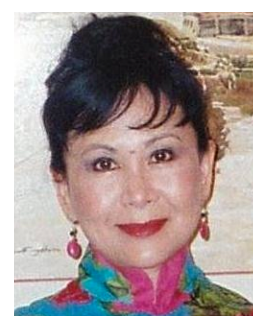

This paper briefly discusses the prospects of using coastal wetlands as REDD+ projects for small island states. The paper contends that the city-state of Singapore would do well to enhance existing laws to more specifically address the challenges and threats faced in conserving mangroves and inter-tidal mudflats, and support their conservation and rehabilitation, not just to facilitate the implementation of REDD+ projects but also to meet other goals like biodiversity conservation and climate change adaptation. The proposal is to expand Sungei Buloh to encompass the mudflats at Kranji which is home to the mangrove horseshoe crab (Carcinoscrorpius rotundicauda); aligned with inter-tidal and coastal management strategies advanced under the auspices of the Ramsar Convention, the Convention on Biological Diversity and the IUCN. However, there are considerable challenges in maintaining an intact eco-system in the face of rapid development, not only in Singapore itself but also in the neighbouring state of Johor, Malaysia. The paper examines the specific legal strategies that will be required to meet the various objectives of conservation in the context of Singapore's laws and the challenges posed by the development plans of both Singapore and Malaysia. ${ }^{1}$

\section{Introduction}

In 1971, the world community formally recognised the value of wetlands through the Convention on Wetlands of International Importance especially as Waterfowl Habitat ('Ramsar Convention'), ${ }^{2}$ and the importance of ensuring their conservation through 'wise use'. Today, some forty years after the signing of the Ramsar Convention, 163 nations have become parties and 2062 sites have been designated worldwide as 'wetlands of international importance'. ${ }^{3}$ In recent years, environmental economists have sought to assess and assign monetary value to the many functions of wetlands as deserving of 'payment for eco-system services' (PES). Scientists now also recognise that coastal wetlands serve as valuable stores of carbon (Blue (arbon) $)^{4}$ adding to the impetus to protect and conserve wetlands, as their destruction will contribute to global warming through the release of carbon dioxide $\left(\mathrm{CO}_{2}\right)$ into the atmosphere.

\footnotetext{
1 The writers acknowledge the contributions of the scientific perspectives in this paper by Assistant Professor Dr Dan Friess, Department of Geography, National University of Singapore.

2 Convention on Wetlands of International Importance Especially as Waterfowl Habitat, opened for signature 2 February 1971, I-14583 (entered into force 21 December 1975) ('Ramsar Convention'). The Preamble to the Ramsar Convention states:

'CONSIDERING the fundamental ecological functions of wetlands as regulators of water regimes and as habitats supporting a characteristic flora and fauna, especially waterfowl;

BEING CONVINCED that wetlands constitute a resource of great economic, cultural, scientific, and recreational value, the loss of which would be irreparable ...'

3 See, About the Ramsar Convention, The Ramsar Convention on Wetlands <http://www.ramsar.org/cda/en/ramsarabout-about-ramsar/main/ramsar/1-36\%5E7687_4000_0__.

4 The carbon sequestered in vegetated coastal ecosystems, specifically mangrove forests, seagrass beds, and salt marshes, has been termed 'blue carbon'. See Elizabeth McLeod et al, ‘A Blueprint for Blue Carbon: Toward an Improved Understanding of the Role of Vegetated Coastal Habitat in Sequestering CO2' (2011) 9(10) Frontiers in Ecology and the 
Climate change was a major concern at Rio in $1992^{5}$ and was specifically addressed in the UN Framework Convention on Climate Change ('UNFCCC'), ${ }^{6}$ which included domestic forest activities within the calculation for emissions in the 1997 Kyoto Protocol. ${ }^{7}$ However, the true integration of climate change issues with conservation of forests and biodiversity only commenced with the COP-11 negotiations in Bali in $2007^{8}$ when the Reduction of Emissions from Deforestation and Degradation (REDD) ${ }^{9}$ was discussed in some detail. Subsequently, REDD became REDD+; the '+' in REDD+ signifies an extension of REDD. REDD+ is a program to establish measurable and verifiable reduction of emissions from deforestation and forest degradation as well as sustainable management of forests, conservation of forest carbon stocks and enhancement of carbon stocks. Successful REDD+ projects require the involvement of populations whose livelihoods derive from forests, such as indigenous peoples and forest-dependent communities.

However, REDD and REDD + were conceived in the context of terrestrial forests, not coastal wetlands, including inter-tidal mudflats and mangroves. REDD+, as originally conceived, does not include the possibility of offsetting emissions from developed countries. This paper argues that REDD+ can and should apply to coastal wetlands, including mangroves and inter-tidal mudflats. The question is whether REDD+ should also apply to offsetting emissions from developed countries - after all, the global community as a whole benefits from reduced emissions. In this context, refraining from destroying or modifying coastal wetlands will conserve carbon that would otherwise be released into the atmosphere. Can a developed country offset its carbon emissions by utilising the eco-system services of other countries? ${ }^{10}$

While it is acknowledged that the implementation of REDD + in relation to coastal wetlands will pose considerable problems from scientific as well as legal perspectives, there is considerable potential for the implementation of REDD+ projects for coastal wetlands. This is particularly relevant for small island states which are especially vulnerable to sea level rise and need to protect as well as enhance their coastal wetlands to serve as natural barriers against storm surges. Additionally, given that small island states are unlikely, because of their size, to have large areas of terrestrial forest cover, mangroves and mudflats are likely to contain a large portion of the stored carbon available to them for conservation. Accordingly, in terms of income generation from reduced emissions, coastal carbon offers these states perhaps the only viable option for participating in REDD+ projects.

\section{Unique challenges for the application of REDD+ to wetlands}

There are many challenges to application of REDD+ to coastal wetlands. Significantly there is a need to improve scientific understanding of the underlying mechanisms that control carbon sequestration in these ecosystems. ${ }^{11}$ Characteristics of coastal wetlands that challenge the application of REDD+ include:

- Not all mangroves accumulate carbon, and rates of forest floor accretion are directly linked to the frequency of tidal inundation.

- Most of the carbon in tropical wetlands is stored below ground, presenting particular difficulties for rapid and accurate measurement for monitoring, reporting and verification (MRV).

- Natural ecosystems change over time but this is often not considered in schemes for the payment of ecosystem services (PES) and REDD+. This is particularly relevant for tropical mangrove forests, as shorelines are constantly evolving and sea-levels rise and fall. ${ }^{12}$

Environment 552. See also Roger Ullman, Vasco Bilbao-Bastida and Gabriel Grimsditch, 'Including Blue Carbon in Climate Market Mechanisms' (2012) (in press), Ocean \& Coastal Management.

5 United Nations Conference on Environment and Development (UNCED), Rio de Janeiro, 3-14 June 1992 (Earth Summit).

${ }^{6}$ United Nations Framework Convention on Climate Change, opened for signature 9 May 1992 (entered into force 21 March 1994), art 2 ('UNFCCC').

7 Kyoto Protocol to the United Nations Framework Convention on Climate Change, opened for signature 10 December 1997 (entered into force 16 February 2005) ('Kyoto Protocol' or 'protocol').

8 UNFCCC, Eleventh meeting of the Conference of the Parties (COP-11), Hyderabad, India 8-19 October 2012.

9 REDD was first mooted in 2005 by the Coalition for Rainforest Nations.

${ }^{10}$ Part of this debate relates to land use, land use change and forestry (LULUCF) activities of developed countries within their own territory under arts 3.3 and 3.4 of the Kyoto Protocol. Discussion has focused in particular on the scope of coverage of emissions from soil and vegetation where non-agricultural/non-forestry wetland soils and vegetation are not covered. See Dave Pritchard, 'REDD - the Link with Wetlands' (Background Paper for FIELD, March 2009) 4.12. See also, LULUCF under the Kyoto Protocol, UNFCCC <http://unfccc.int/methods_and_science/lulucf/items/4129.php>.

${ }^{11}$ See the key areas of uncertainty and specific actions needed to address them in the article by Elizabeth Mcleod et al, above n 4, and Daniel Friess, 'Tropical Wetlands and REDD+: Three Unique Scientific Challenges for Policy' [2013] (special issue). Mangrove dynamics are controlled by externalities; thus, placing a protected area boundary around a mangrove does little to address the root causes of degradation and carbon loss. 
- Large uncertainties exist in carbon sequestration potential of mangroves, and such limitations must be factored into the timeframe and execution of PES and REDD+ schemes. ${ }^{13}$

There is, thus, a call for scientists to 'provide new knowledge to help constrain global $\mathrm{CO}_{2}$ emissions, keep track of the fate of the emitted carbon, and identify and monitor sensitive carbon pools. This information would greatly help support global carbon management'. ${ }^{14}$ Le Quere suggests that an International Carbon Office be set up to oversee and assist with international carbon research activities in collaboration with the Group on Earth Observations to: ${ }^{15}$

- Compile, analyse, report and archive statistics and information on the global and regional balance of $\mathrm{CO}_{2}$ and other greenhouse gases (GHGs).

- Identify and monitor the most important $\mathrm{CO}_{2}$ sinks and natural reservoirs of carbon.

- Facilitate the development of methods that can help to fill the gap in full carbon accounting.

- $\quad$ Reduce uncertainty in existing estimates and provide independent verification of reported emissions.

In essence, it is important for policy makers and lawyers to recognise that, as a consequence of water movement and water serving as an agent of transfer (through tides and currents), mudflats and mangroves are dynamic in nature and are constantly evolving. Environmental values, including the impact of currents, waves and water content, which may have an impact on the viability of a site, are, more often than not, contingent on processes that occur outside designated protected areas and sometimes beyond the scope of national jurisdictions. A key to maintaining the integrity of mudflats and mangroves as repositories of carbon would be to ensure that activities and processes that occur beyond the site have minimal impact on the site; the law has an important role in ensuring this. The concept, for example, of a marine (or intertidal) protected area cannot just involve setting aside a fixed area of land (through zoning) as a protected area and governing activities that occur within that area. The dynamic nature of marine ecosystems (water, waves and currents) would require that protecting a particular area must also involve addressing, as a priority, processes that occur outside that area.

Considering, especially, in relation to mangroves and mudflats, carbon is stored in the soil (mud), the law should seek to limit human activities that encourage sediment outflow. Sediment outflow is caused by, among other things, wave erosion, human induced removal of mud (reclamation, dredging, the construction of coastal fortifications), land-based encroachment, unrestricted human activity on mudflats and the removal of mangroves (the roots of the mangroves assist in binding the mud). It should also seek to limit human activities that facilitate sediment inflow. Sediment inflow can be limited by, among other things, the building of dams, causeways and other coastal fortifications. The law should also seek to limit activities that result in the draining of mudflats and the removal of mangrove vegetation (during reclamation). In this respect, it is important to bear in mind that mangroves, in addition to storing carbon, help to bind mudflats (hence keeping the soil in place) and that the draining of mudflats can lead to carbon loss through water outflow.

In addition, the law should, through the creation of appropriate institutions and mechanisms, seek to facilitate greater understanding of the potential of managing coastal carbon, the challenges that relate to carbon accounting in coastal areas and the dynamics of coastal processes.

The development of such laws must take place with an appreciation for the concerns of biodiversity conservation. There is a risk that, in our haste to introduce laws that address coastal wetland conservation from a carbon sequestration standpoint in order to implement REDD + projects and initiatives, we may not adequately address the need to conserve biodiversity in such wetlands. Furthermore laws introduced to promote REDD+ and carbon sequestration could, if drafted without biodiversity values being adequately considered, have a negative or limiting impact on the conservation of wildlife. The conservation of biodiversity in coastal wetlands has historically been advanced under the Ramsar Convention and the Convention on Biological Diversity ('CBD'). The need to conserve mudflats and mangroves from a biodiversity conservation standpoint has gained momentum because there is an increased awareness that

\footnotetext{
${ }^{12}$ See Daniel M Alongi, 'Carbon Payments for Mangrove Conservation: Ecosystem Constraints and Uncertainties of Sequestration Potential' (2011) 14 Environmental Science and Policy 462. Thus, the temporal scales of carbon dynamics may not fit policy timescales: Friess, above $\mathrm{n} 11$.

13 See above n 11, 12

${ }^{14}$ Corrine Le Quere, 'Filling the Gap in Scientific Institutions to Support Global Carbon Management', Editorial, (2010) 1(1) Carbon Management 5. 
they serve as stopovers for migratory birds, there is increased interest in the conservation of coastal and inter-tidal species, such as horseshoe crabs, and there is also increased appreciation of their potential in generating eco-tourism revenues. In view of the fact that the conservation of mangroves and mudflats is desirable from a carbon sequestration standpoint and, given that there is increased interest in such ecosystems from a biodiversity conservation standpoint, there is a unique opportunity to address both objectives together through legislation and policy initiatives. Furthermore, coastal wetlands render other important ecosystem services, such as the provision of coastal defences, and serving as hatcheries and nurseries for various fish species. These objectives can also be addressed in the context of legal and policy initiatives. From an investment perspective, it is also arguable that REDD+ sites that confer multiple cobenefits may be more attractive to investors, especially those seeking to purchase credits in the context of the voluntary market.

Taking into consideration the unique challenges associated with the conservation of marine and inter-tidal ecosystems, it is essential that a system of laws and legal institutions be designed to address these concerns. This would, at its most basic level, encompass national laws; but since ecological systems do not recognise political boundaries, regional and international collaboration may be necessary. This is certainly pertinent in the case of Singapore's north-west wetlands (Sungei Buloh, which is legally protected as a Nature Reserve and also listed as ASEAN Heritage Park, and the Kranji mudflats) which appear to be closely linked to the ecosystem of Johor's Tanjong Piai, which is a Ramsar site as well as an ASEAN Heritage Park.

\section{Legal frameworks for conservation of wetlands}

The Ramsar Convention is premised on the 'wise use' of wetlands. It is essential for each party to develop national wetland policies to support wise use of wetlands, and address all problems and activities that are related to wetlands in a national context. Each party should review its legal and institutional frameworks to ensure that these are generally compatible with this obligation of wise use. ${ }^{16}$ Ideally, this entails the formation of a review team to:

1. Establish a knowledge base of relevant legal and institutional measures which directly or indirectly affect wetlands. These may be site-specific (for example protected areas, site planning, participatory management) or non-site specific (for example integrated planning, environmental permit systems, impact assessments and audit procedures, habitat and species conservation, incentives). The team should first identify which institutions and agencies have functional responsibility for wetland conservation and wise use, including trans-boundary wetland related issues. There should be institutional coordination between different sectors and levels of government. The mechanisms for trans-boundary and international cooperation should be examined.

2. Assess the effectiveness of existing legal and institutional measures for the promotion of wetland conservation and wise use, as well as analyse how sectoral and institutional measures directly or indirectly affect wetlands. This may require critical evaluation of the processes or activities that adversely affect wetlands, both inside and outside wetlands that result in:

- loss or degradation of wetland area and landscape;

- changes in the water regime (velocity, volume, seasonal flows, ground water etc);

- changes in water quality (pollution, eutrophication, sedimentation etc);

- over-exploitation or disturbance of wetlands and wetland products.

Relevant sectors may include agriculture, forestry, fisheries, public health, energy generation, industry and mining, tourism, land use development, trade and transport, coastal and inland navigation, foreign and domestic investments, foreign affairs and national defence.

In the context of laws, all possible sources of laws should be examined. These include primary laws (statutes) and subsidiary legislation (rules, regulations, notifications), municipal regulations, common law (including case law), customary laws and practice, constitutional provisions, ministerial guidelines, codes of practice, land tenure, rules on resource use, contracts and concessions, religious norms, and obligations under international law. In particular, the team should look out for: - conflicting sectoral policies, laws, taxes and institutional priorities;

- weak or incomplete laws for wetlands, for example no safeguards for water supply of appropriate quality and quantity;

\footnotetext{
${ }^{16}$ Ramsar Convention Secretariat, 'Laws and institutions' (Ramsar Handbook 3,4 $4^{\text {th }}$ ed, 2010).
} 
- land tenure and resource use regimes which undermine wise use;

- ineffective wetland administrative authorities;

- jurisdictional constraints on ecosystem management of river basins and coastal areas;

- lack of effective monitoring procedures, enforcement and remedies;

- lack of provisions for compensation for lost wetland habitats or functions;

- gaps, overlaps and inconsistencies in any of the above.

In essence, the team should examine whether wetlands are effectively protected under the law; whether there are provisions to encourage positive conservation and stewardship, for example conservation easements and tax benefits; whether there are punitive measures to discourage conversion to other uses - for example, in cases where development involves loss of wetlands or degradation, is there a system for compensation consistent with the polluter pays principle and are there remedies available for parties where wetlands are unlawfully destroyed or damaged; do the laws make it an offence to degrade or destroy wetlands etc?

In the context of REDD+, it is also essential to enquire whether, when wetlands are designated as protected areas, the laws allow continued access and use by indigenous and local communities where this is consistent with the conservation and wise use of the site. Are the laws supportive of customary practices, tenure systems and institutions of indigenous and local communities which are sustainable? Do users of wetlands, including indigenous and local communities, have the right to information, representation and participation in site management? Do the laws require or support the preparation and implementation of wetland management plans?

3. Recommend necessary changes to support wetland conservation and wise use:

- remove legal and institutional measures contributing to loss of wetlands;

- implement existing measures more effectively;

- prioritise areas where laws and institutions should be upgraded;

Here it is essential that there be vertical as well as horizontal coordination between wetland administrative agencies and sectoral departments and agencies as well as between different tiers of government. There should be coordination and integration in the management of inland water systems (river basins, water catchments, water sheds) and coastal areas. The administrative authorities should have sufficient resources (human and technical) to implement wetland conservation and wise-use programs.

4. Examine possible transboundary and international cooperation. Here the team should examine if there are effective means to coordinate and share the management of shared wetlands, watercourses or flora and fauna; the question is whether institutional and joint management can be made more effective and strengthened. Development aid programs should not support activities that damage wetlands and should support wise use.

5. Lastly, the review team should identify and prioritise the areas where laws and institutions should be upgraded or consolidated, or where new legislative or economic instruments should be developed

\section{Legal solutions}

In the context of framing laws for the wise use of wetlands, the following guidelines are suggested: ${ }^{17}$

\section{A. Establishing appropriate frameworks for the conservation of coastal wetlands;}

1. Central to the conservation of coastal wetlands, given, especially, the dynamic nature of marine systems, is the need for an integrated coastal management strategy or policy. All land use and spatial planning in relation to coastal areas, and all activities and objectives in relation to such areas, including those relating to construction, economic development, transportation, biodiversity conservation and carbon sequestration, should fall within an integrated management plan for the entire coast and be considered together and in a holistic manner. This will ensure that, at the

\footnotetext{
${ }^{17}$ Some of the suggestions set out in this part are drawn from broadly similar arguments that were advanced in: European Commission, 'Guidance Document - The Implementation of the Birds and Habitats Directives in Estuaries and Coastal Zones - With Particular Attention to Port Development and Dredging (January 2011); and John MacKinnon, Yvonne I. Verkuil and Nicholas Murray, 'IUCN situation analysis on East and Southeast Asian Intertidal Habitats, with Particular Reference to the Yellow Sea (Including the Bohai Sea) (Occasional Paper of the IUCN, 2012).
} 
planning stage, projects are considered and assessed taking into account their potential impact on carbon and biodiversity conservation and that these concerns are not addressed as part of subsequent efforts to mitigate the negative impacts of coastal development. This, in particular, is key to ensuring that activities in areas that have not been designated for carbon or biodiversity conservation or are unrelated to such conservation do not have an adverse impact on sites designated for such conservation.

2. Trans-boundary treaties are essential for the protection of carbon stocks because threatening processes that may have an impact on the ability of coastal wetlands to accumulate and retain carbon may originate in neighbouring states. Many species rely on adjoining sites in neighbouring countries and connectivity through adjoining waters. In this respect, the Singapore and Johor authorities should initiate talks to protect their coastal wetlands, especially those along the Straits of Johore through collaboration and coordination.

3. Within states, specific frameworks should be established for the conservation, protection and augmentation of coastal wetlands and a broader marine environment protection strategy should be developed to evaluate holistically the use of coastal and marine areas under national jurisdiction and the use, conservation and management of marine resources including blue carbon and marine biodiversity.

4. 'Nature based solutions' should be made central, not just to strategies on coastal defences and climate change adaptation but also in relation to reducing carbon emissions. For example, the conservation, rehabilitation and re-planting of mangroves should be part of the national strategy on carbon sequestration and climate change adaptation. Similarly the conservation of mangroves and inter-tidal areas as hatcheries, nurseries and fisheries reserves should also be embraced nationally as part of a country's resource management strategy.

5. More generally, countries should develop combined strategies on biodiversity and climate change, as opposed to biodiversity strategies that incorporate climate change concerns or climate change strategies that confer incidental benefits on biodiversity conservation. Instead of seeing climate change as a factor that accelerates biodiversity loss, it is also important to identify common values that, if promoted, will ensure both the conservation of biodiversity and the mitigation of humaninduced climate change.

B. Ensuring that appropriate administrative frameworks are in place to facilitate the conservation of coastal wetlands;

1. The creation of a national management authority to evaluate all externalities and threats that individual selected sites are subject to, so that these may be dealt with early or avoided altogether.

2. The creation of a national scientific authority to (a) measure, assess and verify carbon content as potential blue carbon sites (b) evaluate and better understand the challenges of doing so (c) promote education and research into all issues relating to coastal wetlands and blue carbon (d) develop conservation capacity (e) generate publicity and awareness in relation to blue carbon issues, and (f) account for and place a value on the ecosystem services, such as potential carbon credits and tourism that are rendered by coastal wetlands.

3. The development of national (or site specific) management plans for coastal wetlands that (a) look at their conservation and enhancement and which seek to (b) monitor, mitigate and minimise the impact of threatening processes on these sites.

4. The introduction of a coastal management law or code of practice that looks holistically at the impact of human activity on coastal processes and the effect of that (tides, pollution, coastal water content, water values etc) on, among other things, human health, economic growth, carbon stocks and biodiversity.

5. Ensuring, in line with an integrated coastal management framework, that there are mechanisms in place to allow authorities responsible for carbon sequestration and biodiversity conservation to work closely with and cooperate with the authorities responsible for port development and management, urban development and land-use planning. Where possible, it may be helpful to provide jurisdictional clarity in relation to the management of coastal wetlands, particularly in the realms of carbon conservation and biodiversity conservation and to identify the specific authorities responsible.

C. Ensuring that specific threats are addressed through land and coastal use policy:

1. Activities such as land reclamation, coastal dredging and the building of dams that could have an adverse impact on sediment inflow or outflow, or result in the destruction of coastal wetlands and habitats should be properly considered and regulated within the context of an integrated coastal management system. 
2. Land and coastal use regulations must be extended to define what is permitted or prohibited in terms of human activity in and around coastal wetlands. This could involve limiting movement and recreational activities like fishing on mudflats and dealing with the impact of boating and shipping -discussed below. Licenses and permits should be employed to regulate legitimate activities in and around coastal wetlands.

3. Coastal development adjacent to coastal wetlands should be permitted only if developers agree to conserve and/or rehabilitate mangroves adjacent to developments. In this respect, restrictive covenants could be imposed on land development, ownership and use adjacent to coastal wetlands. In this respect, as per article $8(\mathrm{e})$ of the Convention on Biological Diversity ('CBD'), ${ }^{18}$ the law should require sound and sustainable development in areas adjacent to protected areas. The conservation of coastal wetlands can be achieved through conservation concessions granted to academic institutions/NGOs or through site-management agreements. Additionally, tax incentives could be granted to the owners of property located adjacent to coastal wetlands to manage them sustainably, to limit the impact of developmental activity and to conserve them on behalf of the state.

D. Addressing threatening processes through ElAs and mitigating their impact:

1. The introduction of a law mandating environmental impact studies/assessments (EIA) is essential to enable stakeholders to better understand the potential impact of coastal development on carbon and biodiversity values. Given the dynamic nature of the marine systems, maintaining the integrity of carbon habitats/stocks will involve minimising the impact of processes that have an impact on carbon retention or the growth in carbon stocks.

An EIA law relating to marine ecosystems should be broad-based in terms of its scope and:

- Address the impact of reclamation, the construction of sea-walls (these prevent mudflat expansion) and the construction of dams and coastal fortifications that prevent re-silting and result in the increased salination of coastal areas.

- Determine the cumulative impact of projects (with other projects and processes) on carbon values and biodiversity values as opposed to measuring the impact of individual projects or activities in isolation.

- $\quad$ Address the impact of activities not just at the site where potentially threatening processes like dredging and reclamation take place but also at other sites that may, as a consequence of tides, waves and the dynamic nature of marine systems, be affected by these activities. In short, the scope of the EIA must be broad and the investigative powers granted thereunder must be wide.

- Address the impact of activities on coastal processes (eg tide-flows), water quality, water values (salinity, pH levels etc) and human health.

- Assess the impact of development on carbon emissions.

- Allow for continuous monitoring of the impact of projects during and after the development of those projects so that mitigating steps may be taken, where appropriate and possible.

2. Quite apart from requiring EIA procedures to be carried out, the law should require full disclosure and transparency in relation to projects that could influence coastal processes that in turn have an impact on carbon and biodiversity values. In the context of Singapore, it should be noted that Singapore does not have EIA laws but the authorities do conduct environmental impact assessments when deemed necessary. However, there is little transparency and NGOs like the Nature Society are consulted on an ad hoc basis. This has resulted in several last-minute attempts to save ecologically sensitive sites. ${ }^{19}$ Furthermore, as many of the threatening processes that affect coastal wetlands and marine areas are 'less visible' and less understood, stakeholder feedback is especially essential and appropriate frameworks must be established to take on board such feedback. There is much to be said for advancing the argument of the public trust, which is

\footnotetext{
${ }^{18}$ Convention on Biological Diversity, Article 8. In-situ Conservation, UNEP <http://www.cbd.int/convention/articles/default.shtml?a=cbd-08>.

${ }^{19}$ See the proposed reclamation of Chek Jawa in 2002 and the proposed golf course at Lower Peirce Reservoir, a legally protected nature reserve (1992) and the current controversy over an old gravesite, Bukit Brown cited in Lye Lin Heng, 'A Fine City in a Garden - Environmental Law and Governance in Singapore' (2008) Singapore Journal of Legal Studies 68; Lye Lin Heng, 'Nature Conservation Laws - The Legal Protection of Flora and Fauna in Singapore in The Singapore Red Data Book - Threatened Plants and Animals of Singapore (Nature Society, 2008).
} 
premised on viewing the government as trustee of all lands not in private ownership. It follows that the public, as beneficiaries, should be consulted. ${ }^{20}$

3. Where unsustainable activities have to be undertaken, it is essential to ensure that there are measures in place to monitor the impact of such activities so that efforts to mitigate the impact of such activities are undertaken early. Furthermore the law should guarantee that existing processes, like dredging and reclamation, that benefit economic development but which potentially have an impact on carbon and biodiversity values must be undertaken in a manner that is sustainable. The law should further require that where developmental activity involves the reclamation or degradation of mudflats, there are directives in place that require that the mud removed is used to augment other mudflats or to create new ones (sediment re-location). Additionally, the law could provide that carbon lost in clearing mudflats should be replaced or offset by other means, such as re-forestation or the use of clean technologies.

4. Finally, in this respect, penalties imposed under the law in relation to environmental impact and pollution should take into consideration environmental damage, the impact on ecosystem services and ecosystem restoration costs. Conversely, the law should avoid liability models that involve the imposition of fixed penalties that are subject to caps.

\section{E. Biodiversity conservation and coastal wetlands.}

To ensure that coastal wetlands embrace biodiversity values, the law should seek to ensure the following:

1. The creation of inter-tidal protected areas with legislation addressing the specific threats faced by inter-tidal species and the extension and adaptation of existing species protection laws to include marine life forms and to address the threats faced by inter-tidal species. Some of these threats include, poaching, the collection of invertebrates, fishing and wildlife harassment. Where it is not possible to designate habitats as protected areas the law should create other land-use categories (such as the creation of areas of scientific and educational interest) which offer a more limited form of protection.

2. Consider the relationship between inter-tidal ecosystems and nearby terrestrial ecosystems and promote the conservation of these other ecosystems where necessary. Birds, for example, may feed in inter-tidal areas and roost in nearby terrestrial areas. Conservation should therefore not just focus on inter-tidal zones but on broader biospheres. It should ensure that vegetation above the high tide line is not removed because it provides important sites for shore-birds. Similarly, it should address all threats to habitat connectivity and promote the protection of related and adjoining coastal/inter-tidal sites as part of an overall strategy of developing a framework of coastal protected areas. The conservation of a single site may be insufficient as wetland species often move between several sites. For example, birds move back and forth between sites to roost and feed and invertebrates, such as horseshoe crabs, may move back and forth from related habitats.

3. Create a legal basis for restoring and rehabilitating degraded ecosystems (this mirrors Article 8 ( $f$ ) of the $C B D) .{ }^{21}$ In this respect it should ensure that a balance is struck between the planting of mangroves on mudflats for the purposes of climate change adaptation and the values conferred by mudflats independent of mangroves. For example, birds have a need for open mudflats and the over-planting of mudflats with mangroves could be problematic. In summary, the law should ensure that climate change adaptation and carbon sequestration initiatives (even where these are nature based solutions) incorporate biodiversity values.

4. Protect the food sources of migratory birds and other species that use inter-tidal zones (as opposed to just the habitats). The law must deal with alien invasive species (AIS), with authorities given power and resources to deal with all aspects of the problem as they apply to coastal wetlands. ${ }^{22}$

5. Address, through appropriate measures, the threat to coastal wetlands arising from land and seabased pollution. Garbage, sewage, oily mixtures and chemical mixtures all have the ability to 'poison' inter-tidal areas and poison food sources. Discarded nets and plastic bags have the potential to trap and kill various marine creatures such a turtles. The impact of activities that may have an impact on water values, such as $\mathrm{pH}$ and salinity, should be addressed, because such changes could have an adverse impact on biodiversity and ecosystems. Similarly, the impact of activities in coastal areas that generate noise and air pollution and which may, consequently, discourage certain species from visiting a site or affect the viability of coastal wetlands altogether.

\footnotetext{
${ }^{20}$ See Joseph Chun, 'Reclaiming the Public Trust in Singapore' (2005) 17 Singapore Academy of Law Journal 717; Lye Lin Heng, 'Land Law and the Environment - Re-examining the Concept of Ownership and Forging New Rights and Obligations in a Changed World' in K Gray (ed), (Singapore Academy of Law Journal Special Edition, Vol 22, 2010$) 189$. ${ }^{21} \mathrm{CBD}$, above $\mathrm{n} 18$.

${ }^{22}$ AIS in the context of shipping is discussed below.
} 
6. More specifically, the laws should address the impact of shipping on coasts and biodiversity. This would include the impact of (a) waves (b) noise (c) air pollution (d) engine oil and bilge water (e) sediment displacement by moving ships ( $f$ ) small boats resting on mudflats $(g)$ net fishing close to coasts $^{23}$ and $(\mathrm{h})$ the impact of ballast water exchange on the spread of AIS. Even if it is not possible to completely set limits on the impact of shipping activity and vessel movement, the impact of recreational and fishing craft should be considered. For example, recreational boating should be outlawed near protected habitats.

7. Require periodic threat assessments by the authorities in relation to coastal biodiversity. This is in line with article 7 (c) of the CBD which calls for the identification of processes and categories of activities that have or are likely to have significant adverse impacts on the conservation and sustainable use of biological resources. ${ }^{24}$

\section{Implementation of legal frameworks for wetland conservation in singapore}

Singapore has one legally protected wetland site: the Sungei Buloh Wetlands Reserve. It was first made a nature park in 1989, when it was only 89 hectares. It was extended to 130 hectares and gazetted as a nature reserve on 1 January 2002 and renamed Sungei Buloh Wetlands Reserves. ${ }^{25}$ That same year, it was recognised as a site of international importance for migratory birds and part of the East Asian Australasian Shorebird Site Network. It was declared Singapore's first ASEAN Heritage Park in 2003. In December 2008, a draft Master Plan was launched for its expansion, to encompass at least three other mangroves, reservoirs and marshes in the nearby Lim Chu Kang and Kranji areas. It will also be broken up into different zones to cater for different visitors, such as a wetland playground for children and restricted areas for researchers. The Plan was officially launched in June 2010. The existing nature trail will be converted to Sungei Buloh Wetland Park (38 ha) with learning activities for the public. The remaining area, Sungei Buloh Wetland Reserve will become 'a restricted access area to protect its biodiversity'. ${ }^{26}$

While it is laudable that Sungei Buloh is legally protected, this paper calls for an extension of the area of protection to encompass the inter-tidal mudflats at Kranji, which are home to the mangrove horseshoe crab. Specifically, the recommendation is that the area known as Sungei Buloh, which is legally protected as a nature reserve and is designated an ASEAN Heritage Park, be expanded to encompass the inter- tidal mudflats at Kranji for the following reasons:

- The potentially high amount of carbon sequestered in the mudflats of Kranji and the mangroves at Mandai.

- The mudflats of Kranji and the mangroves at Mandai are home (and a critical habitat) of one of the three species of Asian horseshoe crabs (the mangrove horseshoe crab or Carcinoscorpius rotundicauda).

- $\quad$ They are also home to many other mangrove and inter-tidal species.

- The mangroves at Mandai - in terms of species and genetic diversity - are regarded as one of the best (if not the best) in Singapore.

- The entire area from Sungei China to the Mandai Mangroves are part of a Birdlife International designated Important Bird Area (IBA).

- $\quad$ Singapore is a member of the East-Asian Australasian Flyway Partnership and the area from Sungei China to the Mandai Mangroves serves as a stopover site for migratory birds using the East AsianAustralasian Flyway. The flyway supports more migratory waterbird species and a higher proportion that are globally threatened than any other flyway in the world.

- Birds visiting the Sungei Buloh Wetland Reserve move back and forth between the reserve, the mangroves at Mandai and mudflats of Kranji to feed and roost. From an ecological standpoint the three areas and the area extending from Sungei Buloh Wetland Reserve to Sungei China form part of a single ecosystem.

- $\quad$ This would also generally be consistent with inter-tidal and coastal management strategies advanced under the Ramsar Convention and the CBD.

\footnotetext{
${ }^{23}$ Net fishing can contribute towards the by-catch of horseshoe crabs and other inter-tidal species.

${ }^{24}$ Convention on Biological Diversity (CBD), Article 7. Identification and Monitoring UNEP <http://www.cbd.int/convention/articles/default.shtml?a=cbd-07>.

25 The Schedule, Parks and Trees Act, Cap 216, 2006 Rev Ed (Act 4 of 2005) Singapore Statutes <http://statutes.agc.gov.sg/aol/home.w3p>. See also <https://www.sbwr.org.sg/aboutus/ourhistory/>.

26 'Sungei Buloh: Bigger and Better - the Master Plan' (Wild shores of Singapore, 20 June 2010) <http://wildshores.blogspot.sg/2010/06/sungei-buloh-bigger-and-better-master.html>.
} 
The protection accorded to Sungei Buloh should be aligned with inter-tidal and coastal management strategies advanced under the Ramsar Convention, the CBD and the International Union for Conservation of Nature (IUCN). This would accord with the recent passing of three motions at the IUCN Congress on the Conservation of Asian Horseshoe Crabs, Water-bird Monitoring and the Protection of the East AsianAustralasian Flyway. ${ }^{27}$ However it should be noted that, while Singapore is a party to the CBD, it is not a party to the Ramsar Convention. Also note that this part of Singapore could even (given the movement patterns of some species) be viewed ecologically as an extension of the Tanjong Piai site in the nearby Malaysian state of Johor, which was made a Ramsar site in $2003 .{ }^{28}$ However, Johor is establishing a new port in the estuary of Tanjung Piai. It is clear that there are considerable challenges in maintaining an intact eco-system in the face of rapid development. These are challenges that constantly confront and challenge both countries. This paper will now briefly examine the existing hard and soft laws that apply and the challenges posed by the development plans of both Singapore and Malaysia.

\section{Current legal framework in relation to inter-tidal areas in Singapore.}

\section{Land Use in Inter-tidal areas}

The Foreshores Act was passed in 1872 'to provide for reclamations and to validate and facilitate leases or grants of foreshores and submerged lands'. ${ }^{29}$ Section 3 of the Foreshores Act restricts the construction of sea walls, stating that 'No person shall erect or build any sea wall or river wall, or construct any revetment along the bank of any port, river or channel, or erect any permanent building or structure within 15 metres of the foreshore or of any such bank, except in accordance with plans and specifications approved by the Urban Redevelopment Authority'. Only the government may (s 4(1)):

(a) construct quays, wharves, jetties or other public works along or out from the foreshore of Singapore or in the sea-bed adjacent thereto;

(b) dredge the sea-bed; and

(c) erect buildings upon any areas of land reclaimed from the sea ...

The Government may also reclaim 'any part of the foreshore or sea-bed of Singapore' with the permission of Parliament (s 4(2)). However, where the part of foreshore or sea-bed to be reclaimed does not exceed eight ha or, if the whole of that part is within port limits, four hectares (ha), the approval of Parliament is required and the Minister may authorise such reclamation (s 3(2)). The government may also lease 'any part of the foreshore and sea-bed in Singapore or in any tidal river or channel therein' such lease not to exceed 100 years except in special cases (s 9).

The State Lands Encroachment $A c t^{30}$ makes it an offence for anyone to cut, dig or take from any State land any live or dead timber, or other vegetable product, or any beeswax, guano, mineral, gravel, stone, coral, shell, sand, loam, brick-earth or other product. It is also an offence to cut, remove or sell any timber or produce lying or being on state land or strip or remove bark from any tree in any State land. ${ }^{31}$

\section{Protection of wild flora and fauna}

The Wild Animals and Birds Act ${ }^{32}$ protects all wild animals and birds in Singapore with the exception of six species of birds. ${ }^{33}$ It is arguable whether it applies to non-terrestrial species, as it defines 'wild animals and birds' to include 'all species of animals and birds of a wild nature, but does not include domestic dogs and cats, horses, cattle, sheep, goats, domestic pigs, poultry and ducks' (s 2). Applying the ejusdem generis rule, it may be argued that reptiles, invertebrates, as well as marine species may not be protected.

\footnotetext{
27 See IUCN World Conservation Congeress, Resolutions and Recommendations adopted in Jeju (6-15 September 2012) IUCN <http://iucnworldconservationcongress.org/member_s_assembly/resolutions/>.

${ }^{28}$ Tanjung Piai derived its name from the piai raya fern (Acrostichum aureum) which is found in abundance in the mangrove forests there. The site consists of 526 ha of coastal mangroves and 400 ha of inter-tidal mudflats in Pontian, Johor, with a shoreline bordering the Straits of Malacca that stretches some $8 \mathrm{~km}$. See Michael Cheang, 'Protecting Mangrove Sites', The Star (online) 13 May 2003 <http://www.ecologyasia.com/news-archives/2003/may03/thestar_20030513_2.htm>.

${ }^{29}$ See Preamble to the Act, Cap 113, 1985 Rev Ed (Ordinance 8 of 1872).

${ }^{30}$ Cap 315, 1985 Rev, Ed, (Ordinance 10 of 1883).

31 The penalty is a fine not exceeding $\$ \$ 2,000$ (s 14).

${ }^{32}$ Cap 351, 2000 Rev, Ed (Ordinance 5 of 1965).

${ }^{33}$ Section 5 states 'No person shall kill, take or keep any wild animal or bird ...'
} 
The Parks and Trees $\mathrm{Act}^{34}$ establishes two national parks and four nature reserves in Singapore, including the Sungei Buloh Nature Reserve and provides the greatest protection to flora and fauna in these parks and reserves. ${ }^{35}$ The Endangered Species (Import and Export) Act ${ }^{36}$ implements the Convention on International Trade in Endangered Species of Wild Flora and Fauna ('CITES'). ${ }^{37}$ The Fisheries Act, inter alia, prohibits the use of poisons or explosives in fishing (s. 10), or the operation of trawl nets in the territorial waters of Singapore (s 12).

The Environmental Protection and Management Act $^{38}$ governs land-based pollution (air, water, noise, hazardous substances) and the Environmental Public Health Act ${ }^{39}$ governs waste management in Singapore. Marine pollution is governed by the Prevention of Pollution at Sea Act ${ }^{40}$ and the Merchant Shipping Oil Pollution (Civil Liability) Act, ${ }^{41}$ Singapore.

\section{The international legal framework}

Several international instruments and documents give impetus to the need to conserve inter-tidal areas. Those that are more relevant for Singapore are set out below.

\section{Convention on Biological Diversity ('CBD')}

Singapore is a party to the CBD. COP-7 Decision VII/5, on establishing a national framework of marine and coastal protected areas, calls on parties to address, through appropriate integrated marine and coastal management approaches, all threats, including those arising from the land (for example water quality and sedimentation) and shipping/transport, in order to maximise the effectiveness of marine and coastal

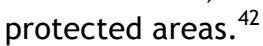

The CBD's Aichi Target 10 requires that, by 2015, the multiple anthropogenic pressures on coral reefs, and other vulnerable ecosystems impacted by climate change or ocean acidification are minimised, so as to maintain their integrity and functioning. Target 11 requires that by 2020, at least 17 per cent of terrestrial and inland water, and 10 per cent of coastal and marine areas, especially areas of particular importance for biodiversity and ecosystem services, are conserved through effectively and equitably managed, ecologically representative and well-connected systems of protected areas and other effective area-based conservation measures, and integrated into the wider landscapes and seascapes. ${ }^{43}$

\section{Ramsar Convention}

Singapore is not a party and it is unclear if it would satisfy the criteria for identifying wetlands of international importance. ${ }^{44}$ However, an attempt should be made to register Sungei Buloh and the possibilities would be enhanced if the area is extended as is proposed in this paper. Resolution 10.22 .13 of the Conference of the Parties calls on parties to review and modify existing policies that adversely affect intertidal wetlands, to introduce measures for the long-term conservation of these areas and to identify and designate as Wetlands of International Importance a greater number and area of intertidal wetlands, especially tidal flats, giving priority to, inter alia, those holding globally threatened wetland species, and Resolution 10.22.23 encourages parties in their efforts to protect such habitats in future and to monitor them and mitigate any past development impacts on or losses to inter-tidal mudflats. ${ }^{45}$

\footnotetext{
${ }^{34}$ Cap 216, 2006 Rev Ed (Act 4 of 2005).

${ }^{35}$ Penalties for breach include a fine of up to $\$ \$ 50,000$ or imprisonment up to six months or both fine and imprisonment (ss. 8 and 9).

${ }^{36}$ Cap 92A, 2008 Rev Ed (Act 5 of 2006).

${ }^{37}$ Under the $A c t$, penalties for breach are a fine of up to $\$ \$ 50,000$ for each scheduled species not to exceed the sum of $\mathrm{S} \$ 500,000$ in the aggregate, or imprisonment of up to two years or both such fine and imprisonment (s 4).

${ }^{38}$ Cap 94A, 2002 Rev, Ed (Act 9 of 1999).

${ }^{39}$ Cap 95, 2002 Rev, Ed (Act 14 of 1987).

${ }^{40}$ Cap 243, 1999 Rev, Ed (Act 18 of 1990)

${ }^{41}$ Cap 180, 1999 Rev, Ed (Act 33 of 1998)

42 See Convention on Biological Diversity, COP 7 Decision VII/5, IUCN

<http://www.cbd.int/decision/cop/default.shtml?id=7742>.

${ }^{43}$ See Convention on Biological Diversity, Aichi Biodiversity Targets, IUCN <http: //www.cbd.int/sp/targets>.

44 See Ramsar, What are the Criteria for Identifying Wetlands of International Importance? <http://www.ramsar.org/cda/en/ramsar-about-faqs-what-are-criteria/main/ramsar/1-36-37\%5E7726_4000_0>.

${ }^{45}$ See Ramsar, Resolution X.22, Promoting International Cooperation for the Conservation of Waterbird Flyways, $10^{\text {th }}$ Meeting of the Conference of the Parties to the Convention on Wetlands (28 October-4 Novembmer 2008) <http://www.ramsar.org/pdf/res/key_res_x_22_e.pdf>.
} 


\section{ASEAN instruments ${ }^{46}$}

A number of ASEAN instruments are relevant. They include :

1. 2007 Singapore Declaration on Climate Change, Energy and the Environment. ${ }^{47}$ This, inter alia, encourages the development of adaptation strategies to mitigate weather-related calamities caused by water and calls for the fostering of the conservation and sustainable management of coastal and marine ecosystems and calls on regional and international communities to participate in efforts to avoid marine pollution, such as marine litter, and the destruction of protected and vulnerable areas such as coral reefs, mangroves, sea grass beds, wetlands and seamounts.

22007 ASEAN Declaration on Environmental Sustainability. ${ }^{48}$ This, inter alia, encourages members to take into account biodiversity in the mitigation of and adaptation to climate change, to support the conservation and management of ASEAN Heritage Parks; and encourages ASEAN Member Countries to identify more Parks and promote conservation and sustainable management of key ecosystems, including forests, coastal, and marine habitats, such as coral reefs, through initiatives, in particular, the 'Heart of Borneo', 49 'Forest Eleven Forum ( $\mathrm{F}-11)$ ', ${ }^{50}$ and the 'Coral Triangle Initiative on Coral Reefs, Fisheries, and Food Security'. ${ }^{11}$

3. ASEAN Common Position Paper on REDD on Developing Countries 2008. ${ }^{52}$ This arose from the Inaugural Workshop on the ASEAN Regional Knowledge Network on Forests and Climate Change held in Jakarta (October 2008). The focus was on forests and it was noted that LULUCF has contributed to global emissions but the current CDM was too narrow and complicated and has prevented ASEAN from successfully participating.

4. ASEAN Common Position Paper on REDD+ on Developing Countries $2010 .{ }^{53}$ This builds on the 2008 REDD position and acknowledged the importance of REDD+ in reducing emissions of GHGs from the atmosphere. It emphasised that REDD+ implementation must be in accordance with the national capabilities and circumstances of developing countries, respect sovereignty and allow developing states to continue with national development. The paper emphasised that a decision on REDD+ at COP-16 should take into account the need for flexible approaches including national accounting with sub-national implementation and a phased approach which allows developing countries to choose the phase to start with and the elements in each phase. Developing states should also be allowed to choose either fund-based, market-based or a combination of these, to accommodate their preferences, levels of readiness and priorities.

5. ASEAN Peatland Management Initiative (2005): ${ }^{54}$ Sustainable Management of Peatlands: Wise Use, Prevention of Fires and Rehabilitation - A Contribution to the Implementation of the ASEAN Agreement on Transboundary Haze Pollution and the ASEAN Regional Haze Plan.

6. ASEAN Peatland Management Strategy (2006-2020): ${ }^{55}$ under the Framework of the ASEAN Peatland Management Initiative (2005). This Strategy identified the common needs regarding peatland management, which include improvement of knowledge of peatland ecosystems, conflicts of interest between local people, industries, and government; improvement of scientific knowledge; improvement of partnerships between stakeholders; and improvement of laws and policies. Both

\footnotetext{
${ }^{46}$ See Koh Kheng Lian, 'Editorial: A Survey of ASEAN Instruments Relating to Peatlands, Mangroves and Other Wetlands: The REDD+ Context' [2013] (Special Edition ) International Journal of Rural Law and Policy.

${ }^{47}$ See ASEAN, Singlapore Declaration on Climate Change, Energy and the Environment (21 November 2007) <http://www.asean.org/asean/external-relations/east-asia-summit-eas/item/singapore-declaration-on-climatechange-energy-and-the-environment>.

${ }^{48}$ See ASEAN, ASEAN Declaration on Environmental Sustainability (21 November 20017)

<http://www.asean.org/news/item/asean-declaration-on-environmental-sustainability>.

${ }^{49}$ See Heart of Boneo, About the HoB Initiative <http://www.hobgreeneconomy.org/en/about/>.

${ }^{50}$ See Forest 11, About Forest-Elevent <http: / / forest-eleven.org/index.php?kode=1>.

${ }^{51}$ See Coral Triangle Initiative: On Coral Reefs, Fisheries and Food Security <http: / /www.coraltriangleinitiative.org/>.

52 See ASEAN, ASEAN Common Position Paper on Reducing Emission from Deforestation and Forest Degradation (REDD) in Developing Countries <http://unfccc.int/files/kyoto_protocol/application/pdf/indonesiaaseanredd060608.pdf>.

${ }^{53}$ Ibid.

${ }^{54}$ See ASEAN, Regional, Sustainable Management of Peatland Forests in Southeast Asia <http://www. peatportal.net/index.cfm?\&menuid=42>; see also ASEAN, About APFP, Sustainable Management of Peatland Forests in Southeast Asia <http://www. aseanpeat.net/index.cfm?\&menuid=38>.

${ }^{55}$ See 2006 ASEAN Peatland Management Strategy, adopted by the Environment Ministers at the $10^{\text {th }}$ ASEAN Ministerial Meeting on the Environment in Cebu, the Philippines (10 November 2006) <http://cil.nus.edu.sg/rp/pdf/2006\%20ASEAN\%20Peatland\%20Management\%20Strategy-pdf.pdf>.
} 
instruments on Peatlands are working towards the goal of a regional strategy to promote sustainable management of peatlands in the ASEAN region through collective actions and enhanced cooperation to support and sustain local livelihoods, reduce risk of fire and associated haze, and contribute to sustainable global environmental management.

7. The 2010 Asean Leaders' Statement on Joint Response to Climate Change. ${ }^{56}$ This Statement calls for the incorporation of mitigation and adaptation strategies into national development strategies and policies in line with sustainable development.

The 2009 PEMSEA Declaration (The Manila Declaration) ${ }^{57}$

This declaration recognised the importance of integrated coastal management for sustainable development and climate change adaptation for the seas of the East Asia region.

The East Asian Australasian Flyway Partnership Agreement ${ }^{58}$

This is a voluntary initiative and Singapore is a signatory to the Agreement. The Flyway supports more migratory water-bird species and a higher proportion that are globally threatened than any other flyway in the world.

\section{Motions adopted at the 2012 IUCN World Conservation Congress}

These are on (a) the conservation of Asian horseshoe crabs, (b) cooperation on water-bird monitoring and (c) the conservation of the East Asian-Australasian Flyway and its threatened water-birds. All three motions relate broadly to the conservation of inter-tidal habitats. ${ }^{59}$

IUCN Situation Analysis on East and Southeast Asian intertidal habitats, with particular reference to the Yellow Sea (including the Bohai Sea) ${ }^{60}$

IUCN's - Mangroves for the Future Program ${ }^{61}$

This program is a post-Tsunami partnership (not directly relevant to Singapore) but another initiative that has given impetus to the idea of using mangroves as coastal defences.

\section{Implementation}

The first step for Singapore would be to extend the area now legally protected as Sungei Buloh Wetlands Reserve, to encompass the Kranji and Mandai mutflats as suggested here. In addition, existing laws should be enhanced, along the recommendations outlined above, to provide for better protection for the flora and fauna in these reserves. There is also merit in extending protection to the area of Tanjong Piai, Johor, as it forms part of the ecosystem. This will require a collaborative arrangement between the Singapore and Malay governments and the passing of relevant laws. However, this raises transnational issues and political and economic sensitivities; perhaps to be resolved when there is greater appreciation for the many benefits of conserving wetlands and these benefits can be seen to outweigh the economic advantages of converting them for other uses such as ports and industries. It is hoped that this realisation does not come too late for both parties.

\section{Conclusion}

The law can, in a myriad of ways, support the conservation of inter-tidal mudflats and mangroves and enable them to serve as repositories of carbon. The ability of the law to succeed in this respect - given the

\footnotetext{
${ }^{56}$ See 2010 ASEAN Leaders' Statement on Joint Response to Climate Change adopted on 9 April 2010 in Ha Noi, Vietnam by the Heads of State/Government <http://cil.nus.edu.sg/2010/2010-asean-leaders-statement-on-joint-response-toclimate-change/>

${ }^{57}$ See Manila Declaration on the Peaceful Settlement of International Disputes, $37^{\text {th }}$ sess, Agenda Item 1222 , UN Doc A/RES/37/10 (15 November 1982).

${ }^{58}$ Department of Sustainability, Environment, Water, Population and Communities, East Asian - Australasian Flyway Partnership, Migratory Speicies in Australia

<http://www.environment.gov.au/biodiversity/migratory/waterbirds/flyway-partnership/index.html>.

59 See above $n 23$.

${ }^{60}$ See John McKinnon, Yvonne I Verkuil and Nicholas Murray, IUCN Situation Analysis on East and Souteast Asian Intertidal Habitats, with Particular Reference to the Yellow Seas

<http://cmsdata.iucn.org/downloads/iucn_situation_analysis_mackinnonverkuilmurray_draft_for_review_1.pdf>.

${ }^{61}$ IUCN, Mangroves for the Future: Investing in Coastal Ecosystems

<http://www.iucn.org/about/union/secretariat/offices/asia/regional_activities/mangroves_for_the_future/>.
} 
nature of marine systems and processes - will involve policy makers in having to take a strategic and holistic coastal management approach to the conservation of mud-flats, and to evaluate the impact of a wide range of activities, projects and processes. Nevertheless, given the biodiversity and climate-change adaptation benefits of conserving inter-tidal mudflats and mangroves, their conservation is a laudable goal. Many of the legal solutions put forward in this paper represent available options and particular solutions to some of the challenges that lawmakers will have to address in attaining these benefits. 